\title{
Serum Levels of Classical HLA Class I Antigen in HIV-Infected Patients During Antiretroviral Therapy. Correlation with the Clinical Outcome
}

\author{
G. Murdaca, P. Cagnati, F. Puppo \\ Department of Internal Medicine, University of Genova, \\ Viale Benedetto XV 6, 16132 Genova, Italy
}

KEYWORDS: Soluble HLA Molecules; HIV;AIDS; HAART

\begin{abstract}
Aim. Human major histocompatibility complex class I antigens (HLA-A, $-B$, and $-C$ ) are heterodimeric molecules composed of a a heavy chain noncovalently associated with an invariant protein known as $\beta_{2}$-microglobulin. Besides being expressed on the membrane of the large majority of nucleated cells, HLA class I antigens are found in serum (sHLA-I). We have previously detected a significant increase in the serum level of $\beta_{2}$ microglobulin-associated HLA-I antigens in HIVinfected patients as compared to HIV-negative controls.

Materials and methods. The introduction of the Highly Active Antiretroviral Therapy (HAART) has modified the clinical course of the disease and decreased the AIDS-related morbidity and mortality. Therefore, we measured the levels of sHLA-I antigens in 64 HIV-infected patients before and during HAART treatment. and correlated them with the imunological and virological response to the antiretroviral treatment.

Results and conclusion. Serum sHLA-I antigen level was elevated in all HIV-infected subjects before and significantly decreased after 36 months of HAART treatment correlating with the decrease of plasma HIV-RNA level and with the increase of CD4+Tlymphocyte number. These results suggest that the measurement of sHLA-I antigens serum level might represent $a$ useful surrogate marker to monitor HIV-positive subjects undergoing HAART treatment
\end{abstract}

\section{Introduction}

Human major histocompatibility complex class I antigens ( $H L A-A,-B$, and $-C$ ) are heterodimeric molecules composed of a 44-kD polymorphic glycoprotein (a chain) noncovalently associated with a $12-\mathrm{kD}$ invariant protein known as $b_{2}$-microglobulin $\left(\beta_{2}-\mu\right)[1]$. The a chain consists of three extracellular domains, one transmembrane domain and one intracytoplasmic domain. Besides being expressed
[1-3]. HLA class I antigens are found in serum (sHLA-I). The molecular mass of sHLA-I heavy chains ranges from 44 to $35 \mathrm{kD}[1,4-9]$.

The 44-kD species are probably intact HLA-I heavy chains that circulate in lipid-associated form [1,4-9]. The 39-kD species, which do not contain the transmembrane portion of the HLA-I heavy chain, are generated by an alternative RNAsplicing pathway and are secreted in soluble form [1,6,7].The 35-kD species contain neither the transmembrane segment nor the cytoplasmic tail of the HLA-I heavy chain and are likely to be proteolytic breakdown products of cellular and/or serum 44-kD heavy chains $[1,9]$. The serum $\beta_{2}-\mu$ level has been shown to be increased in patients with human immunodeficiency virus (HIV)-I infection and to represent a marker of disease progression [1,10-12]. Moreover, we have previously reported that the serum level of $\beta_{2}-\mu$-associated HLA-I antigens is significantly elevated in HIV-infected subjects as compared to HIV-negative controls [I], and that its increase correlates with disease progression and development of the Acquired Immunodeficiency Syndrome (AIDS) [I].

The introduction of the Highly Active Antiretroviral Therapy (HAART) has strongly decreased the AIDS-related morbidity and mortality. Therefore, in the present study, we measured serum SHLA-I antigens in a large cohort of HIVinfected patients and correlated their level with the immunological and virological response to the antiretroviral treatment. Serum levels of soluble tumor necrosis factor- $\alpha$ receptor-II ( $80 \mathrm{kDa}$, sTNFR-II) were also evaluated in a subgroup of HIV-infected patients.

\section{Materials and Methods}

\section{Patients}

Sixty four HIV-infected patients ( 41 males and 23 females, mean age $37.6 \pm 9.3$ years) were enrolled. Among them, twenty eight were intravenous drug users ( 18 males and 10 females); twenty eight were heterosexuals (15 males and 13 females) and eight were male homosexuals. Forty six subjects were asymptomatic (CDC stage $A$ ), six were symptomatic (CDC stage $B$ ) and twelve have developed AIDS-defining events (CDC stage C) (Table I). Inclusion criteria were: age above 18 years, known HIVinfection for more than 6 months, negative pregnancy test 
and written informed consent. Patients were consecutively enrolled from 1995 to 1997. Patients were treated with highly active antiretroviral therapy (HAART) according to the Department of Health and Human Services (DHHS) guidelines utilizing the drugs available at the time of their enrolment.

The following immunological and virological parameters have been evaluated at baseline $\left(T_{0}\right)$ and every 3 months after starting antiretroviral therapy up to 36 months $\left(T_{3}\right.$ to $T_{36}$ ): a) lymphocyte membrane phenotype; b) plasma HIVRNA level; c) sHLA-I antigen serum level.

Serum sTNFR-II levels were also measured in 30 out of 64 HIV-infected patients ( 18 males and 12 females; 14 intravenous drug users, 12 heterosexuals, 4 male homosexuals) belonging to CDC stage $A(n .10), C D C$ stage $B(n .10)$ and $C D C$ stage $C(n .10)$, at baseline $\left(T_{0}\right)$ and every 3 months after starting antiretroviral therapy up to 24 months $\left(T_{3}\right.$ to $\left.T_{24}\right)$.

\section{Lymphocyte membrane phenotype}

Lymphocyte membrane phenotype was evaluated by means of whole blood direct immunofluorescence technique and flow cytometric analysis. Briefly, samples of $100 \mu \mathrm{l}$ of uncoagulated whole blood were incubated with fluorescein-isothiocyanate (FITC)-conjugated monoclonal antibodies (mAb) directed to CD3, CD8, CD45 (Caltag,Valter Occhiena, Italy) and CD2 (IL, Italy) antigens or with phycoerythrin (PE)-conjugated $\mathrm{mAb}$ directed to CD4, CD I4, CD56, HLA-DR (Caltag,Valter Occhiena, Italy) and CDI9 (IL, Italy) antigens and with their FITC or PE isotypic controls.After fixation and red cell lysis by an automated cell preparator (Coulter Q-prep-Hialeah, Fiorida), samples were analysed by an EPICS-XL flow cytometer (Coulter-Hialeah, Florida). Both rate of positive cells and mean fluorescence intensity (antigen membrane density) were evaluated. Lymphocytes have been identified by CD45 high density surface expression, monocytes have been identified by low density CD45 expression and CDI4 positivity. Results were expressed as percentage of positive cells, while the absolute numbers of the peripheral CD4+ and CD8+T-lymphocytes were expressed as cells $/ \mathrm{mm}^{3}$.

\section{Plasma HIV-RNA level}

Plasma HIV-RNA level was evaluated by a quantitative reverse transcriptase polymerase chain reaction assay (Nuclisens HIV-I QT, Biomerieux, Marcy L'Etoile, France). Results were expressed as copies/ml and for the statistical analysis undetectable plasma HIV-RNA levels were considered 80 copies $/ \mathrm{ml}$.

\section{sHLA-I antigen level}

sHLA-I serum level was determined by a previously described double determinant immunoassay [13] with minor modifications. All sera were kept frozen at $-80^{\circ} \mathrm{C}$ until use. Briefly, 96-well round-bottomed, flexible polyvinylchloride microtiter plates (Dynatech, Alexandria, VA, USA) were coated overnight at $4^{\circ} \mathrm{C}$ with $50 \mu \mathrm{l}$ of

\begin{tabular}{|c|c|c|c|}
\hline & \multicolumn{3}{|c|}{ Stage } \\
\hline & $\mathbf{A}$ & B & $\mathbf{C}$ \\
\hline $\mathrm{N}^{\circ}$ & 46 & 6 & 12 \\
\hline Male/Female & $32 / 14$ & 2-apr & 7-mag \\
\hline Age (mean \pm SD) & $36.7 \pm 9.2$ & $38.3 \pm 6.8$ & $40.5 \pm 10.8$ \\
\hline \begin{tabular}{|l|} 
Drug user \\
(male/female)
\end{tabular} & 13-giu & l-gen & 4-mar \\
\hline \begin{tabular}{|l|}
$\begin{array}{l}\text { Heterosexual } \\
\text { (male/female) }\end{array}$ \\
\end{tabular} & 13-ago & $0 / 3$ & 2-feb \\
\hline Male homosexual & 6 & $T$ & 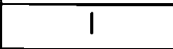 \\
\hline $\begin{array}{l}\text { sHLA-I } \mu g / m l \\
\text { (mean } \pm \text { SD) }\end{array}$ & $0.94 \pm 0.75$ & $0.85 \pm 0.60$ & $1.44 \pm 2.12$ \\
\hline (median) & 0.745 & 0.580 & 0.649 \\
\hline 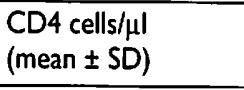 & $469 \pm 240 *$ & $191 \pm 124$ & $101 \pm 100$ \\
\hline (median) & 444 & 188 & 68 \\
\hline $\begin{array}{l}\text { CD4 \% } \\
(\text { mean } \pm \text { SD) }\end{array}$ & $26.0 \pm 10.1^{\circ}$ & $16.0 \pm 8.5$ & $12.5 \pm 8.6$ \\
\hline (median) & 25.0 & 14.5 & 12.5 \\
\hline $\begin{array}{l}C D 8 \% \\
(\text { mean } \pm \text { SD) }\end{array}$ & $43.4 \pm 5.9^{\wedge}$ & $47.3 \pm 8.5$ & $51.5 \pm 8.1$ \\
\hline (median) & 42.0 & 49.0 & 53.5 \\
\hline $\begin{array}{l}\text { HIV-RNA copies/ml } \\
\text { (mean } \pm \text { SD) }\end{array}$ & $65315 \pm 41176$ & $62667 \pm 48525$ & $62808 \pm 42078$ \\
\hline (median) & 80000 & 79000 & 74500 \\
\hline
\end{tabular}

Table 1 - Characteristics of HIV-infected patients. $* A$ vs $B, p=0.0245 ; A$ vs $C, p<0.0001 ;{ }^{\circ} A$ vs $C, p=0.0005 ; \wedge A$ vs $C, p=0.0067$

purified anti-HLA class IW6/32 mAb [14] $(30 \mu \mathrm{g} / \mathrm{ml}$ in 0.01 $\mathrm{M} \mathrm{NaHCO}_{3}$ buffer, $\mathrm{pH}$ 9.5). The plates were washed three times with $0.5 \%$ PBS-Tween $\mathrm{pH} 7.4$ (PBS-Tw) before blocking with $50 \mu$ l of $3 \%$ low-fat milk/PBS-Tw for I hour at $37^{\circ} \mathrm{C}$. The serum samples were then diluted $1: 1$ in $1.5 \%$ low-fat milk/PBS-Tw and $50 \mu \mathrm{l}$ were added in triplicates and the plates were incubated for an additional I hour at $37^{\circ} \mathrm{C}$. The biotynilated anti- $\beta_{2} \mu$ NAMB-I mAb [15] was diluted to $5 \mu \mathrm{g} / \mathrm{ml}$ in $1.5 \%$ low-fat milk/PBS-Tw and $100 \mu \mathrm{l}$ were added to each well. Plates were incubated for $I$ hour at $37^{\circ}$ C. Streptavidin-horseradish peroxidase ( $50 \mu$; Amersham, UK) diluted to $1: 1000$ in 0.1\% BSA/PBS-Tw were added to each well; after $30 \mathrm{~min}$. incubation $50 \mu \mathrm{l}$ per well of phosphate-citrate buffer, pH $5.5\left(0.04 \% \mathrm{H}_{2} \mathrm{O}_{2}\right.$ and ophenylenediamine dihydrochloride [Sigma] at $2 \mathrm{mg} / 5 \mathrm{ml}$ of phosphate-citrate buffer) were added. Between each step plates were washed three times in PBS-Tw. The reaction was stopped after $5 \mathrm{~min}$. with $25 \mu \mathrm{l}$ of $36 \% \mathrm{H}_{2} \mathrm{SO}_{4}$ and the optical density was read at $490 \mathrm{~nm}$ in an MR 600 microplate reader (Dynatech). Results were expressed as $\mu \mathrm{g} / \mathrm{ml}$.

\section{Determination of SHLA-I isoforms}

Plasma samples immunoprecipitated with W6/32 mAb coupled to $\mathrm{CN}-\mathrm{Br}$ Sepharose 4B were fractionated by SDS-PAGE performed in denaturing conditions. sHLA-I isoforms were determined by a chemioluminescent 
method (ECL Amersham) utilizing the anti-HLA class I heavy chain TP25.99 mAb [16].

sTNFR-Il level

sTNFR-II serum level was determined by immunoassay utilizing a commercially available kit (Bender MedSystems $\mathrm{GmbH}$,Vienna,Austria) and results were expressed as $\mathrm{ng} / \mathrm{ml}$.

\section{Statistical analysis}

Results are expressed as mean \pm SD.The following nonparametric tests were employed by reason of poor sample size, non-normality of variables and/or non-equality of the variances in CDC stages: a) Kruskal-Wallis test with internal comparisons to compare baseline values; $b$ ) Friedman test with internal comparisons to evaluate variations from $T_{0}$ to $\left.T_{36} ; c\right)$ Wilcoxon signed rank test to match $T_{36}$ vs $T_{0}$ values; $\left.d\right)$ Pearson coefficient to investigate the correlations among the variables. The significant level was taken as $\mathrm{a}=0.05$.

\section{Results}

\section{Lymphocyte membrane phenotype}

The mean percentage and absolute number of CD4+ Tlymphocytes significantly increased from $T_{0}$ to $T_{18}(P<$ 0.0001 ) in all CDC stages; then the mean percentage and the absolute number of CD4+ T-cell remained stable up to $T_{36}$. The mean percentage of CD8+ $T$ lymphocytes significantly decreased from $T_{0}$ to $T_{36}$ in all $C D C$ stages $(P<$ 0.0001 ) (Figure I).
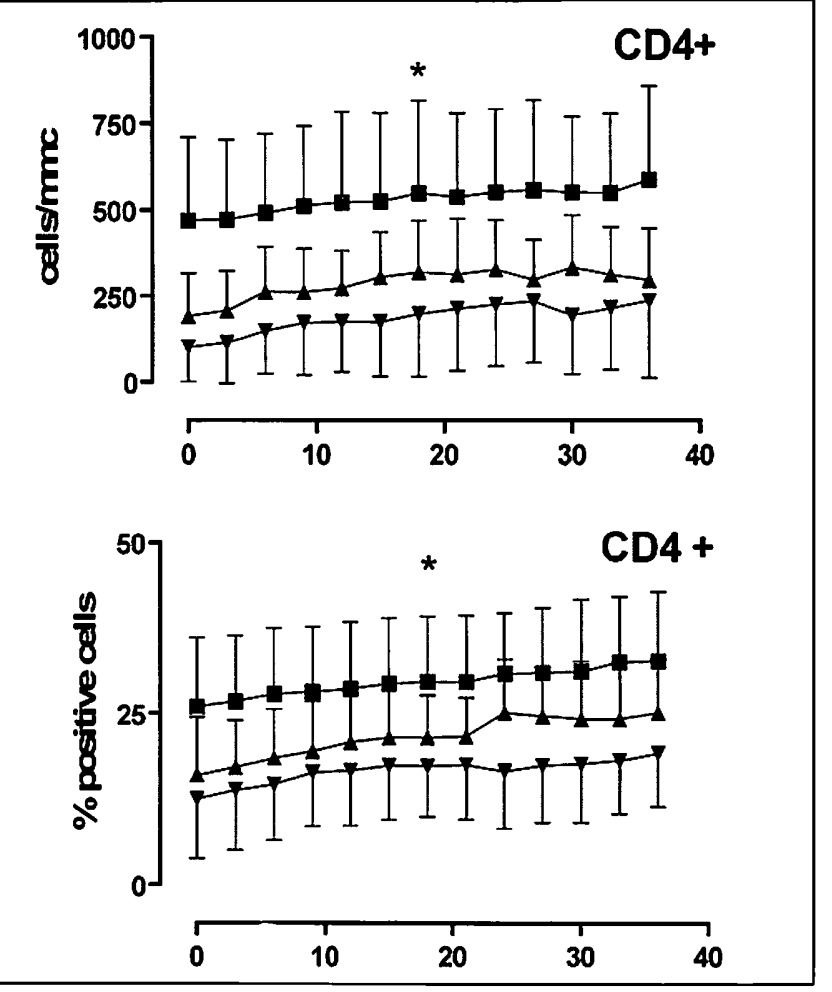

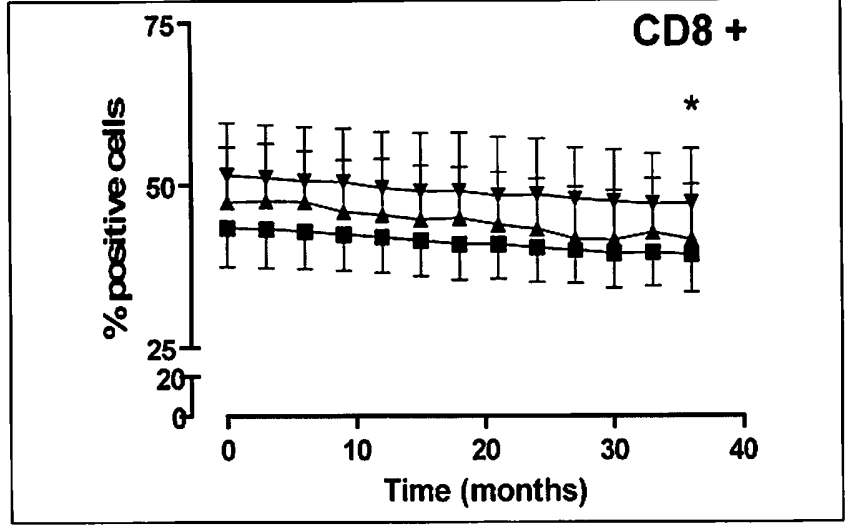

Figure 1 - Peripheral blood T-lymphocyte counts in HIV+ subjects belonging to $C D C$ stage $A(\boldsymbol{D}), B(\Delta)$ and $C(\nabla)$ before and during HAART therapy; $* P<0.0001$ vs. TO.
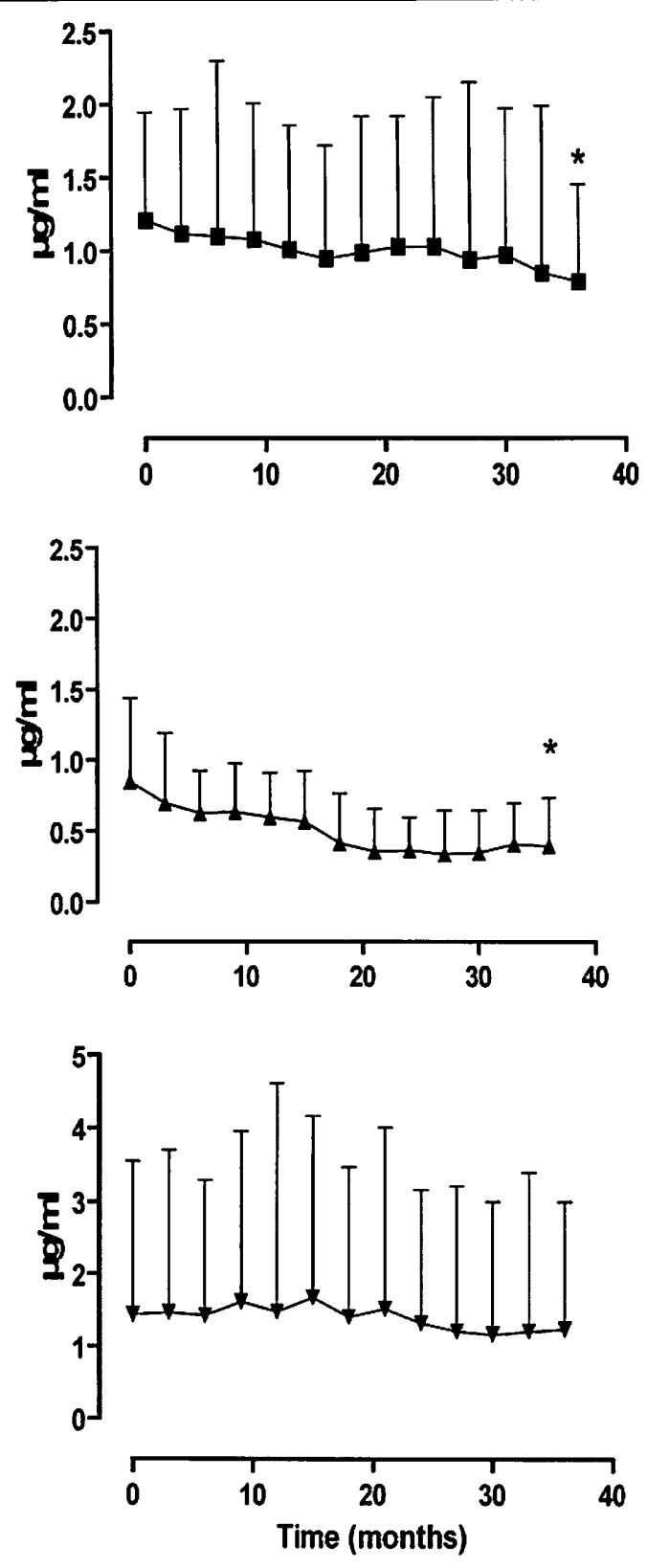

Figure 2 - Behaviour of sHLA-l antigen serum levels in HIV+ subjects belonging to $C D C$ stage $A(\nabla), B(\Delta)$ and $C(\nabla)$ before and during HAART therapy; $* P=0.02$ vs. TO. 


\section{Plasma HIV-RNA levels}

Mean plasma HIV-RNA level was $64,597 \pm 41,333$ copies $/ \mathrm{ml}$ at $\mathrm{T}_{0}$. Then, progressively decreased from $\mathrm{T}_{3}$ to $T_{36}$ in subjects belonging to $C D C$ stages $A$ and $B$, and from $T_{3}$ to $T_{18}$, in subjects belonging to $C D C$ stage $C$, becoming undetectable $(<80$ copies $/ \mathrm{ml})$ in 55 out of the 64 patients at $\mathrm{T}_{36}(\mathrm{P}<0.000 \mathrm{I})$.

\section{sHLA-I antigen levels}

Mean sHLA-I antigen levels at $T_{0}$ were higher in subjects in $C D C$ stage $C$ as compared to those in CDC stages $A$ and $B$, although the difference did not reach the statistical significance. (Table I). Mean sHLA-I antigen levels decreased from $T_{0}$ to $T_{36}$ in all three groups of subjects. In $C D C$ stage $A$ and $B$ subjects the decrease was statistically significant $(I .21$ $\mu \mathrm{g} / \mathrm{ml}$ vs. $0.79 \mu \mathrm{g} / \mathrm{ml}, \mathrm{P}=0.02$ and $0.85 \mu \mathrm{g} / \mathrm{ml} \mathrm{vs} .0 .40 \mu \mathrm{g} / \mathrm{ml}$, $P=0.02$, respectively), whereas in $C D C$ stage $C$ subjects the decrease did not reach the statistical significance $(1.44 \mathrm{mg} / \mathrm{ml}$ vs. $1.24 \mu \mathrm{g} / \mathrm{ml}$ ) (Figure 2).

The decrease in SHLA-I antigen levels correlated with the decrease in plasma HIV-RNA levels in patients belonging to $C D C$ stage $C$ and $B(r=0.281, P=0.0005$ and $r=0.0223$, $P=0.0507$, respectively). Of note, sHLA-I antigen levels remained elevated $(1.55 \pm 2.1)$ in the nine subjects with detectable plasma HIV-RNA levels at $T_{36}$ (from 540 to 10,000 copies $/ \mathrm{ml}$ ).

Furthermore, an inverse correlation was found between sHLA-I antigen levels and the percentage and absolute number of CD4+ T-lymphocytes, whereas a positive correlation was found between SHLA-I antigen levels and the percentage of $\mathrm{CD} 8+\mathrm{T}$-lymphocytes. These correlation reached the statistical significance in subjects belonging to $C D C$ stage $C$ (sHLA-I vs. CD4+ percentage: $r=-0.289$, $P=0.0003 ;$ sHLA-I vs. $C D 4+$ absolute number: $r=0.287, P$ $=0.0004$ ) and CDC stage $B$ (sHLA-I vs. CD4+ absolute number: $r=-0.298, P=0.0390$ ).

\section{sHLA-l isoforms}

The determination of sHLA-I isoforms was performed in 6 patients belonging to $C D C$ stage $A$ (n. 2), CDC stage $B$ (n. 2) and $C D C$ stage $C(n .2)$, respectively. $A$ progressive decrease of all isoforms was detected during HAART therapy. Of note, the 44-kD and the 35-kD isoforms showed the most remarkable reduction and were almost undetectable after 36 months of therapy.

\section{sTNFR-II levels}

Mean sTNFR-II levels did not differ at $T_{0}$ and did not significantly change during HAART among subjects belonging to $C D C$ stages $A, B$ and $C$ (Figure 3 ).

\section{Discussion}

We have previously reported that the serum level of sHLAI antigens are higher in HIV-positive subjects than in healthy controls and that peripheral blood mononuclear cells (PBMC) from HIV-infected individuals spontaneously shed a significant higher amount of sHLA-I molecules than PBMC from HIV-negative subjects [ $I$ ]. We have also shown that the sHLA-I antigen level in HIV-positive patients correlates with disease stage, is predictive of AIDS development and increases with disease progression $[1,17]$. The prognostic value of SHLA-I antigen level agrees with the previously described correlation between the increase in serum $\beta_{2}-\mu$ level and the risk of progression to AIDS in HIV-positive homosexual men $[18,19]$. Therefore, we have hypothesized that the elevated sHLA-I antigens serum levels detected in HIV-infected patients may reflect an accelerated turnover and shedding of HLA class I molecules from PBMC activated in vivo during HIV infection and that SHLA-I molecules secretion may further increase during infectious episodes which occur in the course of HIV disease $[1,17]$.

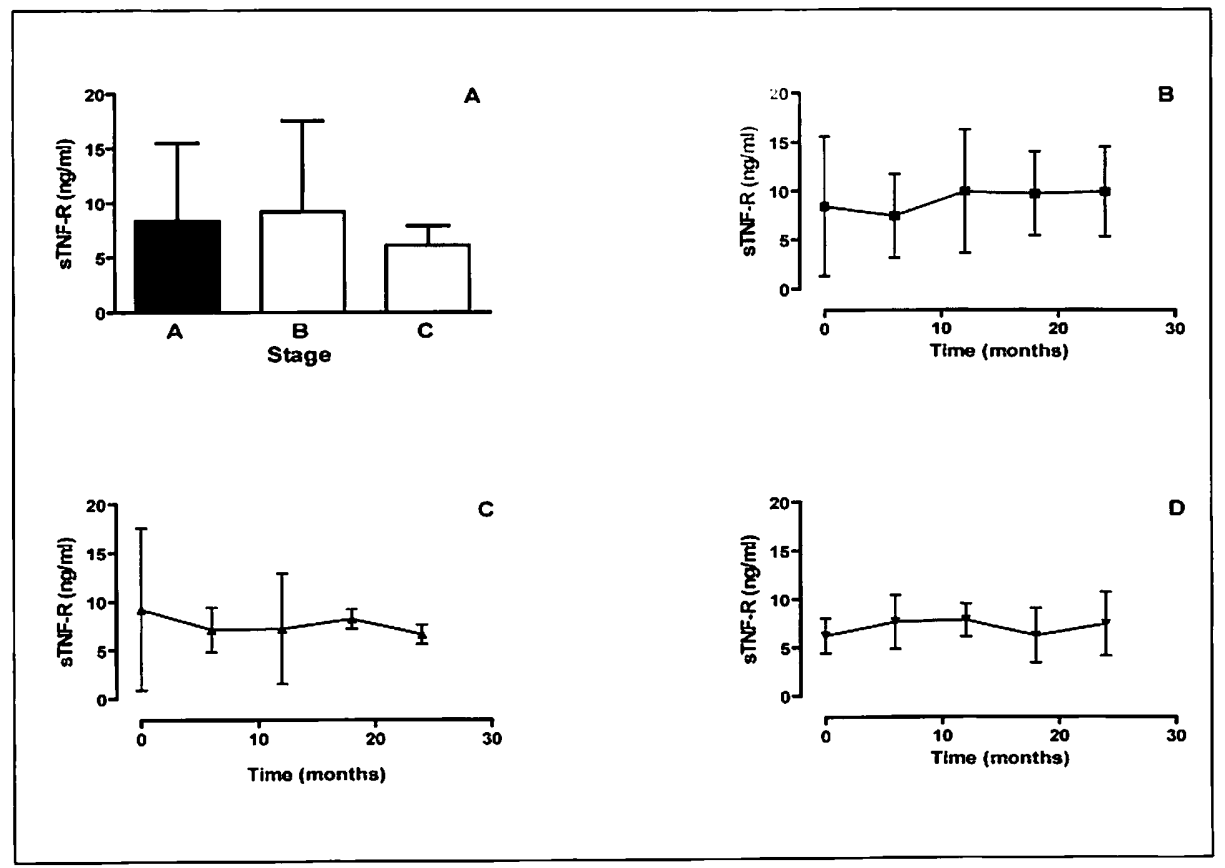

Figure 3. Serum levels of sTNFR-II at baseline (panel $A$ ) and during HAART therapy in HIV+ subjects belonging to $C D C$ stage $A, B$ and $C$ (panels $B, C$ and $D$, respectively). 
At least two lines of evidence suggest that the increased sHLA-I serum level found in viral diseases is determined by the increased endogenous production of interferons and/or other cytokines associated with viral infections. First, cytokines that enhance or induce cell-surface expression of HLA class I antigens have similar effect on their shedding by some, although not all, types of cells (e.g. melanoma cells) [20]. Second, the administration of interferons for therapeutic purposes induces an increase in the level of sHLA-I antigens [2I]. Lastly, more recent evidence suggests the potential involvement of sHLA-I antigens in various steps of the immune response. In particular, it has been reported that sHLA-I antigens inhibit the lytic activity of HLA class I antigen-restricted cytotoxic T lymphocytes and induce apoptosis in CD8+ lymphocytes and natural killer (NK) cells [22-27]. Thus, the increase in the serum level of sHLA-I antigens may play a role in the pathogenesis of HIV disease inhibiting the cytotoxic activity of HLA class Irestricted $C D 8+T$ lymphocytes that recognize antigens expressed by HIV-infected CD4+T cells [28].

In this study, we determined sHLA-I antigen levels in a cohort of 64 HIV-positive subjects and correlated them with the immunological and virological response to the antiretroviral treatment. The introduction of the HAART regimens has decreased the AIDS-related morbidity and mortality, favouring the increase in peripheral blood CD4+ T-lymphocyte count and the suppression of viral replication. As expected, CD4+ T-cell count significantly increased in all patients and plasma HIV-RNA levels were undetectable in 55 out of 64 after 36 months of treatment. At baseline, sHLA-I antigen level was higher in CDC stage $C$ than in CDC stage $A$ and $B$ patients, confirming that sHLA-I measure is an independent marker of disease progression. During treatment, sHLA-I antigen level decreased in all three groups of HIV-infected individuals, achieving a statistically significant reduction in CDC stage $A$ and $B$ patients at $T_{36}$. Moreover, sHLA-I antigen level showed a positive correlation with peripheral blood CD4+ and CD8+ T-lymphocyte number and an inverse correlation with plasma HIV-RNA levels reaching the highest significance in CDC stage $C$ patients. Of note, serum sHLA-I antigens remained elevated in the nine subjects in whom high plasma HIV-RNA levels were still detectable after 36 months of antiretroviral therapy.

The relevance of sHLA-I serum level as an independent surrogate marker of disease progression was further strenghtened by the finding that the serum level of another soluble marker of immune activation, like sTNFR-II [29], did not differ among HIV-positive subjects in different stages of disease and were not modified by HAART.

As far as the determination of SHLA-I isoforms is

concerned, a progressive decrease of all isoforms was detected during HAART in agreement with the reduction of serum sHLA-I antigen level. Notably, the 44-kD and the $35-k D$ isoforms showed the most remarkable reduction and were almost undetectable after 36 months of therapy. Therefore, we suggest that the behaviour of serum sHLA-I molecules during HAART is mainly attributable to both the reduction of HLA class I molecules turnover in PBMC membrane and immune cell apoptotic death. This hypothesis is in agreement with previous reports indicating that a large number of immune cells undergo apoptosis in the course of HIV infection and that antiretroviral drugs might counteract this process [30,3I].

It has been known for some time that SHLA-I molecules are immunogenic, both in allogeneic and xenogeneic hosts [IT]. More recent evidence suggests the potential involvement of sHLA-I antigens in various steps of the immune response. Indeed, sHLA-I antigens block anti-HLAI antibodies and inhibit the cytotoxicity of alloreactive cytotoxic T-lymphocytes (CTLs) [22-24]. The inhibitory effects of sHLA-I antigens on CTLs may occur through multiple mechanisms, including receptor blockade, binding to CD8 molecules via their $\alpha_{3}$ domain and induction of apoptosis [25-27]. Furthermore, the report that a genetically engineered sHLA-B7 molecule can induce specific tolerance suggests an additional mechanism by which circulating HLA-I antigens can modulate immune responses [32]. Therefore, the decrease of sHLA-I serum level detectable in the course of HAART treatment could positively affect CTL response favouring their cytotoxic activity against pathogens. To confirm these findings, nonclassical soluble HLA-G (sHLA-G) will be measured in the serum of the same patients. Elevated serum levels of nonclassical sHLA-G molecules may exert immunomodulatory effects as proven in pregnancy and some neoplastic diseases.

In conclusion, our data confirm that elevated amounts of sHLA-I antigens are detectable in serum of HIV-positive subjects and that the measurement of sHLA-I antigens serum level might represent a useful surrogate marker to monitor the immunoriconstitution and virological response of HIV-positive subjects undergoing HAART treatment.

\section{References}

[I] Puppo F., Brenci S., Lanza L., Bosco O., Imro M.A., Scudeletti M., Indiveri F., Ferrone S. Increased level of serum HLA class I antigens in HIV infection. Correlation with disease progression. Hum. Immunol. 1994, 40: 259.

[2] Krangel M.S., Orr H.T., Strominger J.L.Assembly and maturation of HLA-A and HLA-B antigens in vivo. Cell 1979, 18: 979.

[3] Ploegh H.L., Orr H.T., Strominger J.L. Major histocompatibilty antigens: the human (HLA-A, $-B,-C)$ and murine $(H-2 k, H-2 D)$ class I molecules. Cell 1981, 24: 287.

[4] Allison J.P., Pellegrino M.A., Ferrone S., Callahan G.N., Reisfeld R.A. Biologic and chemical characterization of HLA antigens in human serum. J. Immunol. 1977, I 18: 1004.

[5] Pellegrino M.A., Russo C..Allison J.P. HLA antigens in serum. Methods Enzymol. 1984, 108:614.

[6] Krangel M.S. Secretion of HLA-A and-B antigens via an alternative RNA splicing pathway. J. Exp. Med. 1986, I63: I 173. [7] Krangel M.S. Two forms of HLA class I molecules in human plasma. Hum. Immunol. 1987, 20: 155.

[8] Singh P.B., Brown R.E., Roser B. Class I transplantation antigens in solution in body fluids and in the urine: individuality signals to the environment. J. Exp. Med. 1988, 168: 195.

[9] Dobbe L.M.E., Stam N.J., Neefjes J.J., Giphart M.J. Biochemical 
complexity of serum HLA class I molecules. Immunogenetics 1988, 27: 203.

[10] Bhalla R.B., Safai B., Mertelsmann R., Schwarts M.K. Abnormally high concentration of $\beta_{2}$-microglobulin in acquired immunodeficiency syndrome (AIDS) patients. Clin. Chem. 1983, 29: 1560 .

[I I] Zolla-Pazner S.,William D., El-SadrW., Marmor M., Stahl R. Quantitation of $\beta_{2}$-microglobulin and other immune characteristics in a perspective study of men at high risk for acquired immune deficiency syndrome. JAMA 1984, 251:2951. [12] Fahey J.L., Taylor J.M.G., Detels R., Hofmann B., Melmed R., Nishanian P., Giorgi J.V.The prognostic value of cellular and serologic markers in infection with human immunodeficiency virus type I. N. Engl. J. Med. 1990, 322: 166.

[13] Russo C., Fotino M., Carbonara A.. Ferrone S.A double determinant immunoassay for HLA class I typing using serum as an antigen source. Hum. Immunol. 1987, 19:69.

[14] Barnstable C.J., Bodmer W.F., Brown G., Galfre G., Milstein C., Williams A. F., Ziegler A.Z. Production of monoclonal antibodies to group $A$ erythrocytes, HLA and other human cell surface antigens: new tools for genetic analysis. Cell. 1978, 14:9. [15] Pellegrino M.A., Ng A.K., Russo C., Ferrone S. Heterogeneous distribution of determinants defined by monoclonal antibodies on HLA-A and B antigens bearing molecules. Transplantation 1982. 34: 18.

[16] Tanabe M., Sekimata M., Ferrone S., Takiguchi M. Structural and functional analysis of monomorphic determinants recognized by monoclonal antibodies reacting with the HLA class I $\alpha 3$ domain. J. Immunol. 1992, 148: 3202-3209.

[17] Puppo F., Scudeletti M., Indiveri F., Ferrone S. Serum HLA class I antigens: marker and modulators of an immune response? Immunol Today 1995, 16: 124.

[18] Lifson A.R., Hessol N.A., Buchbinder S.P., ÒMalley P.M., Barnhart L., Segal M., Kats M.H., Holmberg S.D. Serum $\beta_{2^{-}}$ microglobulin and prediction of progression to AIDS in HIV infection. Lancet 1992, 339: 1436.

[19] Anderson R.E., Lang W., Shiboski S., Royce R., Jewell N., Winkelstein W. Use of $\beta_{2}$-microglobulin level and CD4 lymphocyte count to predict development of acquired immunodeficiency syndrome in persons with human immunodeficiency infection. Arch. Intern. Med. 1990, I50: 73. [20] Maio M., Gulwani B., Langer J.A., Kerbel R.S., Duigou G.J., Fisher P.B., Ferrone S. Modulation by interferons of HLA antigen, high-molecular weight melanoma associated antigen, and intercellular adhesion molecule I expression by cultured melanoma cells with different metastatic potential. Cancer Res. 1989, 49: 2980.
[2I] Aulitzky W.E., Grosse-Wilde H., Westhoff U., Tilg H., Aulitzky W., Gastl G. Enhanced serum levels of soluble HLA class I molecules are induced by treatment with recombinant interferongamma (IFN-gamma). Clin. Exp. Immunol. 1991, 86: 236.

[22] Hausmann R., Zavazava N., Steinmann J., Müller-Ruchholts W. Interaction of papain-digested HLA class I molecules with human alloreactive cytotoxic T lymphocytes (CTL). Clin. Exp. Immunol. 1993. 91: 183.

[23] Nixon D.F., McMichael A.J. Cytotoxic T-cell recognition of HIV proteins and peptides.AIDS 1991, 5: 1049.

[24] Parham P., Clayberger C., Zorn S.L., Ludwig D.S., Schoolnik G.K.. Krensky A.M. Inhibition of alloreactive cytotoxic T lymphocytes by peptides from the alpha 2 domain of HLA-A2. Nature 1987, 325:625.

[25] Spaggiari G.M., Contini P., Carosio R., Arvigo M., Ghio M., Oddone D., Dondero A., Zocchi M.R., Puppo F., Indiveri F., Poggi A. Soluble HLA class I molecules induce Natural Killer cell apoptosis through the engagement of $C D 8$. Evidence for a negative regulation exerted by CD94/NKG2A complex and KIR2D. Blood 2002, 99: 1706.

[26] Contini P.. Ghio M., Poggi A., Filaci G., Indiveri F., Ferrone S., Puppo F. Soluble HLA-A,-B,-C and -G molecules induce apoptosis in $\mathrm{T}$ and $\mathrm{NK} \mathrm{CD8}{ }^{+}$cells and inhibit cytotoxic $\mathrm{T}$ cell activity through CD8 ligation. Eur. J. Immunol. 2003, 33: 125.

[27] Contini P., Ghio M., Merlo M., Poggi A., Indiveri F., Puppo F. Apoptosis of antigen-apecific $T$ lymphocytes upon the engagement of CD8 by soluble HLA Class I molecules is Fas Ligand/Fas mediated: evidence for the involvement of $\mathrm{p} 56^{\mathrm{lck}}$, calcium calmodulin kinase II, and calcium-independent protein kinase $C$ signaling pathways and for NF-KB and NF-AT nuclear translocation. J. Immunol. 2005, 175: 7244.

[28] Puppo F., Brenci S., Montinaro E., Lanza L., Contini P., Scudeletti M., Indiveri F. Inhibition of alloreactive cytotoxic T cell activity by HIV-positive sera: potential role of circulating soluble HLA class I molecules. AIDS Res. Hum. Retrovir. 1994, 10: 1061. [29] Sulkowski M.S., Chaisson R.E., Karp C.L., Moore R.D., Margolick J.B., Quinn T.C.The effect of acute infectious illnesses on plasma human immunodeficiency virus (HIV) type I load and the expression of serologic markers of immune activation among HIV-infected adults. J. Infect. Dis. 1998, 178(6): 1642-1648.

[30] Gougeon M.L.Apoptosis as an HIV strategy to escape immune attack. Nat. Rev. Immunol. 2003, 3: 392.

[31] Badley A.D. In vitro and in vivo effects of HIV protease inhibitors on apoptosis. Cell Death Differ. 2005, 12: 924.

[32] Grumet F.C., Krishnaswamy S., See-Tho K., Filvaroff E., Hiraki D.D. Soluble form of an HLA-B7 class I antigen specifically suppresses human alloimmunization. Hum. Immunol. 1994, 40: 228, 1194. 